\title{
Optimizing E-Learning to Improve Digital Literacy of The Third Elementary School Students
}

\section{Ihdina Khusnasani}

Universitas Sebelas Maret khusnasani08@gmail.com

\section{Article History}

received 30/4/2021

\begin{abstract}
The purpose of this research are to improve students' digital literacy and to describe how to optimize e-learning which can improve digital literacy of the third grade students of SDN 1 Giripurwo Kulon Progo in academic year 2020/2021. This research is an action research which was conducted in two cycles. Each cycle has four steps: planning step, action step, observation and reflection. The subjects of the research were 22 third-grade students of SDN 1 Giripurwo Kulon Progo. Data collection techniques used in this research were observation and documentation. Based on the result of the research, it can be concluded that the optimizing elearning can improve digital literacy of the third-grade students of SDN 1 Giripurwo Kulon Progo in academic year 2020/2021, while the way of optimizing e-learning which can improve digital literacy should follow the procedure of distance learning.
\end{abstract}

Keywords: e-learning, distance learning, digital literacy

\section{Abstrak}

Tujuan penelitian ini adalah untuk meningkatkan literasi digital dan mendeskripsikan cara mengoptimalkan e-learning yang dapat meningkatkan literasi digital pada siswa kelas III SDN 1 Giripurwo Kulon Progo tahun ajaran 2020/2021. Penelitian ini merupakan penelitian tindakan kelas yang dilaksanakan dalam dua siklus. Setiap siklus terdiri dari empat tahap, yaitu: tahap perencanaan, pelaksanaan tindakan, observasi, dan refleksi. Subjek penelitian dari penelitian yang akan dilaksanakan ini adalah siswa kelas III SDN 1 Giripurwo Kulon Progo yang berjumlah 22 siswa. Teknik pengumpulan data yang digunakan adalah observasi dan dokumentasi. Berdasarkan hasil penelitian, dapat disimpulkan bahwa pengoptimalan elearning dapat meningkatkan literasi digital pada siswa kelas III SDN 1 Giripurwo Kulon Progo tahun ajaran 2020/2021, sedangkan cara mengoptimalkan e-learning yang dapat meningkatkan literasi digital harus dilakukan sesuai dengan prosedur langkah-langkah pembelajaran jarak jauh.

Kata kunci: e-learning,pembelajaran jarak jauh, literasi digital 


\section{PENDAHULUAN}

Pandemi Coronavirus Disease 2019 (Covid-19) yang terjadi sejak kuartal pertama tahun 2020 di Indonesia membuat pemerintah mengeluarkan kebijakan pembatasan jarak dan pergerakan manusia yang berdampak pada bidang pendidikan. Pada tanggal 24 maret 2020 Menteri Pendidikan dan Kebudayaan Republik Indonesia mengeluarkan Surat Edaran Nomor 4 Tahun 2020 Tentang Pelaksanaan Kebijakan Pendidikan Dalam Masa Darurat Penyebaran COVID. Dalam surat edaran tersebut dijelaskan bahwa proses belajar dilaksanakan di rumah melalui pembelajaran daring atau jarak jauh dilaksanakan untuk memberikan pengalaman belajar yang bermakna bagi peserta didik. Kondisi tersebut menjadikan semua peserta didik beserta guru harus melakukan pembelajaran jarak jauh.

Pembelajaran Jarak Jauh (PJJ) adalah pembelajaran dengan menggunakan suatu media yang memungkinkan terjadinya interaksi antara pengajar dan pembelajar (Prawiyogi, 2020). Pengajar dan pembelajar tidak bertatap muka langsung sehingga bisa berada di tempat yang berbeda dan terpisah jarak.Teknologi digital merupakan media yang berperan penting dalam pelaksanaan PJJ. Pembelajaran jarak jauh atau bisa disebut pembelajaran daring tentu memiliki kelebihan dan kekurangan. Marchovic menyebutkan kelebihan pembelajaran daring dibandingkan pembelajaran luring ialah: 1) aksesibilitas lebih luas; 2) proses pembelajaran dapat belangsung lebih cepat; 3) membangun lingkungan belajar yang kolaboratif dan eksploratif; 4) menghemat waktu dan biaya; 5) akses dapat dikontrol; dan 6) dapat mengakses langsung ke banyak sumber. Disisi lain kekurangannya yaitu: 1) harus tersedia akses server web atau internet yang memadai; 2) perlu waktu untuk mempersiapkan aplikasi pendukung; 3)penilaian dan umpan balik siswa terbatas; dan 4) perlu sumber daya yang manguasai internet of things (Kelana 2021). Pembelajaran jarak jauh akan berjalan lancar jika tingkat literasi digital pendidik dan peserta didik dalam kategori baik. Gilster mendefinisikan literasi digital sebagai suatu kemampuan untuk memahami dan menggunakan informasi dari berbagai sumber digital (Munir, 2017).

Berdasarkan hasil observasi tingkat literasi digital peserta didik saat pelaksanaan PJJ hanya terdapat 1 peserta didik atau sekitar (4,54\%) yang mendapatkan kategori sangat baik, 2 peserta didik atau sekitar (9,09\%) mendapatkan kategori baik, 3 peserta didik pada kategori cukup (13,6\%) dan 16 peserta didik atau sekitar $(68,1 \%)$ mendapatkan kategori kurang pada tingkatan literasi digital. Hal ini menunjukkan bahwa literasi digital pada peserta didik kelas III masih rendah karena hanya terdapat 3 dari 22 peserta didik yang tuntas dan masuk dalam kategori baik dan sangat baik, sedangkan 19 peserta didik masih dalam kategori cukup dan kurang.

Sejalan dengan pendapat (Santoso, 2019) yang pernah mengatakan bahwa peserta didik dengan literasi digital baik memiliki sumber informasi yang lebih banyak dan memiliki capaian belajar yang lebih baik menunjukkan bahwa literasi digital yang baik sangat dibutuhkan di masa PJJ. Literasi digital berperan dalam kemampuan mengakses berbagai sumber pembelajaran yang berkualitas. Salah satu media yang dapat digunakan sebagai sumber pembelajaran saat PJJ adalah E-Learning.

E-learning adalah teknologi informasi dan komunikasi untuk mengaktifkan Peserta Didik untuk belajar kapan pun dan di mana pun, Dahiya dalam (Hartanto, 2016). Elearning memiliki dua tipe yaitu: Synchronous dan Asynchronous. Whatsapp dan Zoom meeting merupakan contoh e-learning yang dapat dijadikan media pembelajaran jarak jauh. Aplikasi e-learning yang paling sering digunakan dalam pembelajaran adalah WhatsApp. Suryadi (2018:5) menyatakan bahwa " WhatsApp merupakan sarana dalam berkomunikasi dengan saling bertukar informasi baik pesan teks, gambar, video bahkan telepon." Berdasarkan pendapat tersebut dapat diketahui bahwa WhatsApp memberikan kemudahan dalam menyampaikan suatu informasi. Penggunaan WhatsApp sudah umum di kalangan masyarakat karena penggunaanya yang mudah, akan tetapi keterbatasan fitur dalam WhatsApp sering menyebabkan kendala dalam proses 
pembelajaran. WhatsApp menyediakan fitur yang dapat digunakan untuk melakukan pembelajaran syncronus dan asyncronus terbatas sedangkan zoom meeting menyediakan fitur pembelajaran asyncronus yang lebih mumpuni. Zoom Meeting sendiri merupakan sebuah media pembelajaran menggunakan video (Haqien,2020). Zoom merupakan salah satu aplikasi komunikasi video berbasis cloud computing buatan perusahaan Amerika yang menyediakan layanan konferensi jarak jauh dengan menggabungkan konferensi video, pertemuan online, obrolan, hingga kolaborasi seluler. Penggunaan e-learning saat pembelajaran jarak jauh dengan memanfaatkan teknologi tentu akan sangat membantu proses pembelajaran. Pemanfaatan e-learning dalam pembelajaran juga akan memberikan pengalaman baru bagi para peserta didik yang dapat mengasah keterampilanya dalam penggunaan teknologi.

Berdasarkan uraian di atas, maka peneliti tertarik untuk melakukan penelitian dengan judul Pengoptimalan E-Learning untuk Meningkatkan Literasi Digital Peserta Didik Kelas 3 Sekolah Dasar (Penelitian Tindakan Kelas Pada Peserta Didik Kelas 3 SDN 1 Giripurwo Tahun Ajaran 2020/2021). Tujuan penelitian ini yaitu untuk meningkatkan literasi digital dan memaparkan cara mengoptimalkan e-learning dalam pembelajaran jarak jauh.

\section{METODE}

Penelitian ini dilaksanakan di SDN 1 Giripurwo yang beralamatkan di Desa Giripurwo, Kapanewon Girimulyo, Kabupaten Kulon Progo. Subjek penelitian dari penelitian yang akan dilaksanakan ini adalah siswa kelas III 1 Giripurwo. Jenis penelitian yaitu Penelitian Tindakan Kelas yang dilaksanakan dalam dua siklus, setiap siklusnya terdiri dari empat tahap, yaitu perencanaan, tindakan, observasi dan refleksi.

Sumber data dalam penelitian ini adalah siswa kelas II, silabus, RPP serta dokumentasi. Teknik pengumpulan data yang digunakan adalah dokumentasi dan observasi. Uji validitas data menggunakan validitas isi dan teknik triangulasi yaitu triangulasi sumber dan teknik. Teknik analisis data yang digunakan yaitu model analisis kualitatif menurut Miles dan Huberman (Sugiyono, 2012 : 247-253) yang terdiri dari pengumpulan data, reduksi data, penyajian data dan penarikan kesimpulan. Prosedur penelitian tindakan kelas ini dilaksanakan dua siklus dengan dua pertemuan setiap siklusnya. Penelitian ini menggunakan prosedur penelitian Kemmis dan Taggart (Arikunto, 2013: 137), yaitu terdiri dari tahap perencanaan, pelaksanaan, pengamatan, dan refleksi yang secara rinci disajikan dalam bagan berikut ini.

\section{HASIL DAN PEMBAHASAN}

Penelitian ini dilaksanakan selama dua siklus dengan mengoptimalkan penggunaan e-learning saat pembelajaran jarak jauh. Prosedur dan pelaksanaan pembelajaran dalam penelitian ini didasarkan pada peningkatan literasi digital melalui pengoptimalan e-learning. Gagasan mengenai literasi digital mulai dipopulerkan oleh Gilster pada tahun 1997 sebagaimana dikutip dalam Belshaw (2011) menyatakan bahwa "Digital literacy is the ability to understand and use information in multiple formats from a wide variety of sources when it is presented via computers". E-learning yang digunakan adalah aplikasi WhatsApp dan zoom meeting. Pengoptimalan e-learning dilakukan dengan langkah : (1) Menganalisis kebutuhan pembelajaran untuk mengetahui kekuatan, kelemahan, peluang dan tantangan pembelajaran jarak jauh, (2) Merumuskan strategi yang tepat dalam penggunaan e-learning, (3) Melakukan pengembangan $e-$ learning, (4) Melakukan efektivitas dan efisiensi manajemen e-learning (Albab, 2020).

Hasil observasi pengoptimalan e-learning saat pembelajaran jarak jauh terhadap tingkat literasi digital peserta didik mengalami peningkatan pada setiap siklusnya hingga mencapai indikator kinerja penelitian yang ditargetkan yaitu $82 \%$. Secara rinci, 
Volume 9 Nomor 1 Tahun 2021

persentase hasil observasi peserta didik siklus I sampai siklus II dapat dilihat pada tabel 1.

Tabel 1. Perbandingan Hasil Literasi Digital Antar Siklus

\begin{tabular}{llccc}
\hline No & Kategori & Pratindakan & Siklus I & Siklus II \\
\hline 1 & Kurang & 16 & 9 & 2 \\
2 & Cukup & 3 & 4 & 2 \\
3 & Baik & 2 & 7 & 11 \\
4 & Sangat Baik & 1 & 2 & 7 \\
\hline
\end{tabular}

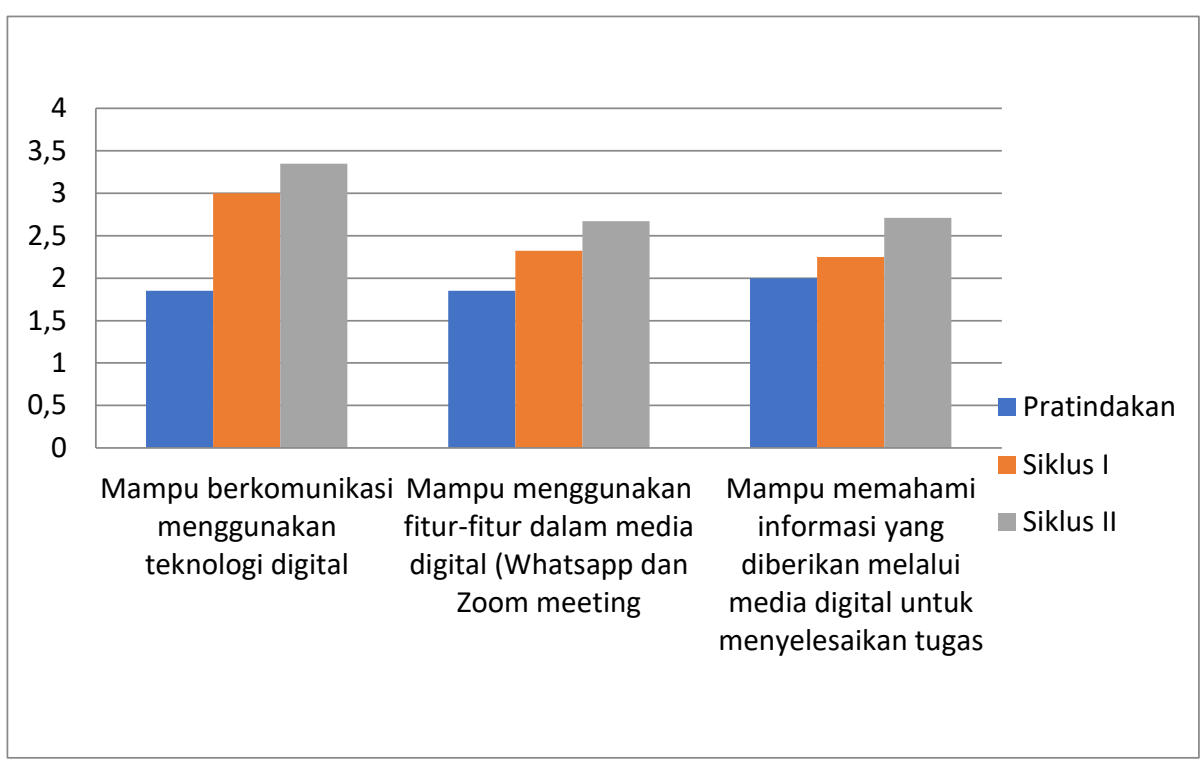

Gambar 1. Diagram Perbandingan Hasil Tindakan

Pada pratindakan tingkat literasi digital hanya sebanyak 3 peserta didik yang mencapai kategori baik dan sangat baik, pada siklus I terdapat 9 peserta didik, dan pada siklus II meningkat menjadi 18 peserta didik . Literasi digital peserta didik kelas III SDN 1 Giripurwo Kulon Progo pada Siklus I sudah mengalami peningkatan dari kondisi awal, namun belum mencapai target yakni $80 \%$. Pada Siklus I ini peserta didik mencapai kategori baik hanya 7 peserta didik 32\%, kategori sangat baik 2 peserta didik 9\% sedangkan pada pratindakan jumlah prosentase kategori baik dan sangat baik hanya sebesar 3 peserta didik 13,63\% Literasi digital peserta didik kelas III SDN 1 Giripurwo Kulon Progo meningkat dari siklus 1 jumlah prosentase kategori baik dan sangat baik yaitu dari $41 \%$ peserta didik pada siklus II sudah menjadi $82 \%$ peserta didik atau meningkat sebesar $41 \%$ dan sudah mencapai indicator ketercapaian penelitian yaitu $80 \%$.

Pada Siklus I setelah dilakukan analisis kebutuhan e-learning maka pembelajaran masih dilakukan menggunakan WhatsApp. Penggunaan WhatsApp akan mempermudah penggunanya untuk menyampaikan suatu informasi secara lebih cepat dan efektif. WhatsApp dapat memberikan keefektifitasan dalam berkomunikasi, 
berinteraksi dengan mudah dan cepat terutama dalam menyampaian informasi pembelajaran (Afnibar, 2020 :73). Observasi pada siklus I menunjukkan bahwa peserta didik mulai terbiasa berkomunikasi dan menyampaikan pesan melalui WhatsApp, merekam dan mengirim pesan suara serta melakukan panggilan video (video call). Meski demikian terdapat cukup banyak peserta didik yang masih perlu pendampingan khusus dalam penggunaan e-learning ini. Fitur Whatsapp yang terbatas Ketika hendak melakukan tatap muka virtual atau kegiatan belajar synchronous menjadi kendala di siklus I.

Pelaksanaan pembelajaran jarak jauh dengan mengoptimalkan penggunaan elearning yang mengalami beberapa kendala yang terjadi pada siklus I yang kemudian diperbaiki pada pelaksanaan siklus II. Kendala tersebut diantaranya; (1) Terbatasnya sarana dalam WhatsApp group sehingga guru hanya bisa membagikan materi tidak menjelaskan secara langsung, (2) Peserta didik masih banyak yang belum lancar berkomunikasi menggunakan whatsapp. (3) Pembelajaran dengan menggunakan panggilan video (whatsapp video call) kurang efektif dan efisien karena harus membagi ke dalam beberapa kelompok dan menjeaskan berulang-ulang. Kendala tersebut telah diperbaiki pada pelaksanaan siklus II.

Setelah dilakukan perumusan strategi, pengembangan e-learning serta manajemen efektifitas dan efisiensi, pada siklus II guru memberikan bimbingan khusus secara langsung kepada orang tua/wali pendamping belajar di rumah dalam menggunakan e-learning. E-learning yang digunakan pasa siklus II yaitu zoom meeting. Zoom memungkinkan peserta didik melakukan kegiatan belajar synchronous dalam jumlah banyak. Ketersedian berbagai fitur pada aplikasi zoom yang juga dapat digunakan dalam proses pembelajaran seperti meeting \& chat, video webinar, conference rooms, phone system, dan marketplace merupakan salah satu kelebihan yang membuat aplikasi ini banyak digunakan sebagai sarana belajar mengajar (Kelana, 2020).

Pada siklus II peserta didik sudah dapat masuk ke dalam zoom meeting dengan lancar. Peserta didik sudah dapat menyalakan serta mematikan microphone sesuai keadaan yang dibutuhkan sehingga komunikasi bisa terjalin dengan baik dan proses pembelajaran berjalan lancar. Peserta didik juga bisa memahami informasi dan teks yang disampaikan oleh guru melalui media digital. Mereka dapat menuliskan kembali gagasan utama dari teks yang diberikan melalui media digital dan dapat menerima instruksi dari guru untuk mengerjakan tugas. Melalui pemantauan diketahu peserta didik dapat mengakses sumber belajar lain yang mendukung penyelesaian tugas. Hal tersebut menunjukan bahwa tingkat literasi digital peserta didik telah meningkat.

Berdasar data hasil observasi dan dokumentasi berupa rekaman pembelajaran menunjukan persentase peserta didik yang telah mampu berkomunikasi menggunakan teknologi digital, mampu menggunakan fitur-fitur dalam media digital (WhatsApp dan zoom meeting), serta mampu memahami informasi yang diberikan melalui media digital untuk menyelesaikan tugas sudah sesuai indikator kinerja penelitian. Literasi digital peserta didik sudah dalam kategori baik. Dengan demikian, tindakan dalam penelitian ini dapat dinyatakan berhasil.

Berdasarkan uraian hasil penelitian di atas, diketahui bahwa pengoptimalan elearning saat pembelajaran jarak jauh dapat meningkatkan literasi digital peserta didik dilihat dari persentase ketercapaian target pada siklus I dan siklus II. Pemanfaatan elearning untuk proses pembelajaran juga membuat peserta didik memiliki pengalaman baru dan membuat pembelajaran lebih bermakna. Pembelajaran jarak jauh dengan mengoptimalkan penggunaan e-learning dapat meningkatkan literasi digital. Hal ini dikarenakan peserta didik dapat langsung praktik menggunakan e-learning dalam proses pembelajaran. Selain itu, pengoptimalan e-learning menjadikan peserta didik lebih antusias dalam mengikuti kegiatan pembelajaran jarak jauh. Literasi digital yang 
baik sangat penting dimiliki di era pembelajaran jarak jauh yang harus memanfaatkan teknologi digital dalam pelaksanaan pembelajaran.

Langkah-langkah perbaikan yang telah dilakukan dalam meningkatkan literasi digital yang mendukung Langkah pengoptimalan e-learning, yaitu: 1) peneliti membuat panduan penginstallan e-learning; 2) peneliti melakukan koordinasi dengan pendamping belajar di rumah masing-masing peserta didik; 3) peneliti menggunakan media yang lebih konkrit agar lebih menarik perhatian peserta didik; 4) peneliti lebih menekankan pembelajaran yang bermakna dan mengajak peserta didik ikut berinteraksi dalam pembelajaran; 5) peneliti menyimpulkan pelajaran dan memberikan penguatan agar peserta didik semakin paham dan dapat menuliskan pesan hasil simakannya menjadi sebuah cerita. Kelebihan penelitian ini dibandingkan dengan penelitian yang relevan adalah penelitian ini tidak monoton dalam menggunakan e-learning atau teknologi digital dan disesuaikan dengan subjek penelitian yaitu peserta didik kelas III SD dengan kondisi pelaksanaan pembelajaran jarak jauh. Selain meningkatkan literasi digital peserta didik, pengoptimalan e-learning juga dapat meningkatkan kualitas pembelajaran jarak jauh.

\section{SIMPULAN}

Berdasarkan hasil penelitian yang telah dilaksanakan dalam dua siklus dan mengoptimalkan penggunaan e-learning dalam pembelajaran jarak jauh pada peserta didik kelas III SDN 1 Giripurwo Kulon Progo dapat ditarik simpulan bahwa pengoptimalan e-learning dapat meningkatkan literasi digital peserta didik kelas III SDN 1 Giripurwo Kulon Progo tahun ajaran 2020/2021.

Cara pengoptimalan e-learning yang dapat meningkatkan literasi digital pada peserta didik kelas III SDN 1 Giripurwo Kulon Progo adalah dilakukan sesuai langkahlankah, model, dan metode yang telah disesuaikan dengan kondisi pembelajaran jarak jauh. Perbaikan yang telah dilakukan untuk meningkatkan literasi digital dengan mengoptimalkan penggunaan e-learning adalah sebagai berikut : 1) peneliti membuat panduan penginstallan e-learning; 2) peneliti melakukan koordinasi dengan pendamping belajar di rumah masing-masing peserta didik; 3) peneliti menggunakan media yang lebih konkrit agar lebih menarik perhatian peserta didik; 4) peneliti lebih menekankan pembelajaran yang bermakna dan mengajak peserta didik ikut berinteraksi dalam pembelajaran; 5) peneliti menyimpulkan pelajaran dan memberikan penguatan agar peserta didik semakin paham dan dapat menuliskan pesan hasil simakannya menjadi sebuah cerita.

\section{DAFTAR PUSTAKA}

Arikunto, S. (2013). Prosedur Penelitian: Suatu Pendekatan Praktik. Jakarta: Rineka Cipta.

Afnibar dan Fajhriani. (2020). Pemanfaatan WhatsApp Sebagai Media Komunikasi Antara Dosen Dan Mahasiswa Dalam Menunjang Kegiatan Belajar (Studi Terhadap Mahasiswa Uin Imam Bonjol Padang. Jurnal Komunikasi dan Penyiaran Islam.Vol.11(1).70-83

Albab, Shobich. 2020. Analisis Kendala Pembelajaran E-Learning Pada Era Disrupsi Di Smk Terpadu Al-Islahiyah Singosari Malang. MUDIR (Jurnal Manajemen Pendidikan) Avalaible online at : http://ejournal.insud.ac.id/index.php/mpi/index Volume 2, Nomor 1, Januari 2020

Belshaw (2011). Digital Literacy.International Journal of Advanced Science and Technology. Vol 29

Haqie, Danin dkk. (2020). Jurnal "Pemanfaatan Zoom Meeting Untuk Proses Pembelajaran Pada Masa Pandemi Covid-19". SAP. Vol. 5 No 1.

Hartanto, W. (2016). Penggunaan ELearningSebagai Media Pembelajaran. Jurnal UNEJ Kelana, Jajang Bayu dkk. (2021). Penggunaan Aplikasi Zoom Meeting Di Masa Pandemi Covid-19 Pada Pembelajaran Sains. Jurnal Elementary Kajian Teori dan Hasil 
Penelitian Pendidikan Sekolah Dasar ISSN 2614-5596 http://journal.ummat.ac.id/index.php/elementary Vol. 4 No. 1 Januari 2021, hal. 1822

Munir. (2017). Pembelajaran Digital. Bandung : Alfabeta.

Prawiyogi, Anggy dkk (2020). Efektifitas Pembelajaran Jarak Jauh Terhadap Pembelajaran Siswa Di Sdit Cendekia Purwakarta. JPD: Jurnal Pendidikan Dasar P-ISSN 2086-7433 E-ISSN 2549-5801 DOI: doi.org/10.21009/JPD.011.10

Santoso, A., dan Lestari, S. 2019. The Roles of Technology Literacy and Technology Integration to Improve Students' Teaching Competencies. KnE Social Sciences. 3(11): 243-256

Sugiyono. (2012). Metode Penelitian Kuantitatif, Kualitatif, dan R\&D. Bandung: Alfabeta Suryadi, dkk.2018. Penggunaan Sosial Media WhatsApp Dan Pengaruhnya Terhadap Disiplin Belajar Peserta Didik Pada Mata Pelajaran Pendidikan Agama Islam. Jurnal Pendidikan Islam. Vol.7 (1). 1-22. Young, R.F. (2007). Crossing Boundaries in Urban Ecology (Doctoral Dissertation). Tersedia dari Proquest Dissertation \& Theses Database. 